\title{
Correlation analysis of preoperative serum alpha-fetoprotein (AFP) level and prognosis of hepatocellular carcinoma (HCC) after hepatectomy
}

Wen-jun Ma ${ }^{1,2}$, Hai-yong Wang ${ }^{1}$ and Li-song Teng ${ }^{1 *}$

\begin{abstract}
Background: To investigate the prediction value of preoperative serum alpha-fetoprotein (AFP) level for the prognosis of hepatocellular carcinoma (HCC), by comparing pathological characteristics, recurrence rate and survival rate after hepatectomy.

Methods: 108 cases of HCC patients who received liver resection in our hospital from 2005 to 2011 were enrolled in this study. According to preoperative serum AFP level, the patients were divided into AFP $\leq 20 \mathrm{ng} / \mathrm{mL}$ group, AFP 20 to $400 \mathrm{ng} / \mathrm{mL}$ group and AFP > $400 \mathrm{ng} / \mathrm{mL}$ group, and the clinicopathological and cytopathological features were compared. All the patients were followed up for 24 months, the postoperative recurrence rates and survival rates were compared and analyzed, and the risk factors for HCC postoperative survival rate were studied by multifactor regression analysis.

Results: Of the 108 cases of HCC patients, there were 42 cases in AFP $\leq 20 \mathrm{ng} / \mathrm{mL}$ group, 28 cases in AFP 20-400 $\mathrm{ng} / \mathrm{mL}$ group and 39 cases in AFP $>400 \mathrm{ng} / \mathrm{mL}$ group. It was shown that cell differentiation degrees $\left(X^{2}=20.198, P=0.000\right)$ and microvascular invasion rates $\left(X^{2}=20.358, P=0.000\right)$ were significantly different among the three groups. The AFP $\leq 20 \mathrm{ng} / \mathrm{mL}$ group showed higher cell differentiation degrees and significantly lower microvascular invasion rates compared to the other groups $(P<0.05)$. The follow-up data showed that postoperative 2 -year recurrence rate $\left(X^{2}=6.164, P=0.046\right)$, 18-month survival rate $\left(X^{2}=7.647, P=0.022\right)$ and 24-month survival rate $\left(X^{2}=6.725, P=0.035\right)$ of the three groups were significantly different, and we found that the AFP $\leq 20 \mathrm{ng} / \mathrm{mL}$ group had lower postoperative 2-year recurrence rate, and higher 18-month survival rate and 24-month survival rate than the other two groups $(P<0.05)$. Multiple logistic regression analysis indicated that tumor diameter $(\geq 5 \mathrm{~cm})$ and preoperative serum AFP level $(>400 \mathrm{ng} / \mathrm{mL}$ ) were closely correlated with HCC postoperative survival rate $(P<0.05)$.
\end{abstract}

Conclusions: It is shown that preoperative serum AFP level has considerable predictive value for the malignant feature and prognosis of HCC. It is suggested that HCC patients with no contraindication of operation and serum AFP $\leq 20 \mathrm{ng} / \mathrm{mL}$ can benefit most from primary treatment of hepatectomy. While HCC patients with serum AFP higher than $20 \mathrm{ng} / \mathrm{mL}$ need comprehensive therapy besides surgical resection and close follow up.

Keywords: Alpha-fetoprotein, Hepatocellular carcinoma, Differentiation degree, Hepatectomy, Prognosis

\footnotetext{
* Correspondence: Isteng@zju.edu.cn

${ }^{1}$ Cancer Center, The First Affiliated Hospital of Zhejiang University School of Medicine, Hangzhou 310003, P.R. China

Full list of author information is available at the end of the article
} 


\section{Background}

Primary liver cancer is one of the common malignant tumors in China and is the second leading malignant tumor with high mortality rates [1]. There are three main types, namely, hepatocellular carcinoma (HCC), bile duct carcinoma and mixed-type $\mathrm{HCC}$, and more than $90 \%$ are HCC. Alpha-fetoprotein (AFP) is a glycoprotein, mainly from the yolk sac and embryo liver; serum AFP levels are very low in adults. Since the 1970s, AFP has been used as a tumor marker for the diagnosis of HCC. Serum AFP levels in nearly $75 \%$ of cases of $\mathrm{HCC}$ are higher than $10 \mathrm{ug} / \mathrm{L}$ [2]. Serum AFP lever is still regarded as the most important serum marker for HCC diagnosis today, though it can be high in some non-cancerous liver disease and can be at a low level in some HCC patients [3,4]. In patients with cirrhosis or chronic hepatitis B or hepatitis $C$ infections, AFP is the most important serum marker to predict liver cancer occurrence $[5,6]$. The serum AFP level not only has diagnostic value but also has predictive value for the prognosis of HCC. As a relatively cheap and mature method, serum AFP has been regarded as an important indicator of postoperative HCC recurrence and metastasis [7]. In addition, a high serum AFP level has been associated with larger tumor size, bilobar involvement, massive or diffuse-type tumors, and portal vein tumor thrombus [8]. Nevertheless, no consistent correlation has been established between serum AFP level and tumor stage, degree of tumor differentiation, or extrahepatic metastasis [9]. In this study, we analyzed the correlation of preoperative serum AFP levels with HCC malignant features and survival after hepatectomy, through 24 months of follow up of 108 patients with $\mathrm{HCC}$, who underwent hepatectomy at a single center.

\section{Methods}

\section{Ethical approval}

This study was approved by the institutional review board (IRB) of the first affiliated hospital of Zhejiang University.

\section{Patient selection}

Patients who underwent hepatectomy for primary liver cancer $(n=108)$ were enrolled in this study. Written informed consent for each patient was given before participating in the study. All patients were diagnosed as primary $\mathrm{HCC}$ on both imaging and histopathological study. All the histopathological diagnoses were confirmed to be HCC with distinctive microscopic features and immunohistochemistry staining results. Patients with serious heart, lung, kidney, or blood diseases, autoimmune liver disease, or the presence of other malignant tumors, were excluded. All the patients underwent surgical resection as their initial treatment. Radical resection was performed in patients with a regional tumor, and patients with a portal vein tumor thrombus received tumor resection plus portal vein thrombectomy or postoperative portal vein perfusion chemotherapy.

\section{Preoperative and postoperative tumor assessment}

Preoperative tumor staging was performed by dynamic computed tomography (CT), assessing tumor size, tumor number, portal vein involvement and regional tumor invasion. Postoperative tumor assessment was made by pathological study of the degree of tumor differentiation, vascular involvement, nerve involvement, lymphatic involvement and non-cancerous liver tissue fibrosis. Adjacent non-cancerous liver tissue was examined by reticular fiber staining, according to the Ishak scoring system (1995) for scoring the degree of fibrosis. Histopathological immunohistochemistry staining of hepatocytes and CK7 were studied by using the EnVision (Zhongshan biotechnology, Beijing) two-step method.

\section{Measurement of serum AFP}

Serum AFP concentrations were determined within 1 month before surgery using a commercially available chemiluminescence immunoassay kit. According to preoperative serum AFP levels, the patients were divided into three groups: (1) AFP negative, AFP $\leq 20 \mathrm{ng} / \mathrm{mL}(\mathrm{n}=41)$; (2) AFP low, AFP $20 \mathrm{ng} / \mathrm{mL}$ to $400 \mathrm{ng} / \mathrm{mL}(\mathrm{n}=28)$; (3) AFP high, AFP > $400 \mathrm{ng} / \mathrm{mL}(\mathrm{n}=39)$.

\section{Follow up}

All the enrolled patients were followed up for 2 years. The postoperative recurrence rate was assessed at 1 and 2 years, and survival was assessed at 6, 12, 18, and 24 months.

\section{Statistical analysis}

All the data were statistically analyzed using the SPSS 15.0 software. Quantitative data were presented as mean \pm SD $(\mathrm{x} \pm \mathrm{s})$. The ages and diameters of tumors in the three groups of patients were compared by analysis of variance; the rate and constituent ratio were compared by the chi-square test; comparisons between two of the three groups with performed by the Student-Newman-Keuls method. Multiple logistic regression analyses were performed to ascertain the independent risk factors for HCC postoperative prognosis. For study time points $\left(t_{\mathrm{K}}\right)$ of 6 , 12, 18, and 24 months after surgery:

Survival rate $=$ Number of survival cases at $t_{K}$ time point/Total number in study.

\section{Results}

\section{Patients' characteristics}

The 108 HCC patients were divided into three groups according to their preoperative serum AFP levels. Age, gender, original liver disease and family history of liver 
disease did not differ between the three groups $(P>0.05)$, as shown in the Table 1.

\section{Preoperative clinicopathologic variables}

The clinicopathologic variables in the three groups of patients, including tumor volume, total tumor diameter, portal vein tumor thrombus, adjacent tissue invasion, and lymph node involvement, were analyzed by statistical software. None of the variables above were statistically different $(P>0.05)$, as shown in the Table 1 .

\section{Pathological features}

The difference in the degree of tumor differentiation and vascular involvement were evaluated by the chi-square test. Both HCC tissue differentiation $\left(X^{2}=20.198, P=\right.$ 0.000 ) and vascular involvement were statistically different $\left(x^{2}=20.358, P=0.000\right)$ among the three groups of patients. Through paired comparison, the differences between the AFP-negative and AFP-low group, and between the AFP-negative and the AFP-high group were both statistically significant $(P<0.05)$, whereas the difference between the AFP-low and AFP-high groups was not $(P>0.05)$, as shown in Table 2 . Differences in nerve involvement, lymphatic involvement, and para-cancerous liver fibrosis, were not statistically significant $(P>0.05)$, as shown in Table 1 .

\section{Follow up}

All patients received consecutive follow up for 2 years. One-year recurrence rates between the three groups of patients showed no statistical difference $\left(\chi^{2}=0.448\right.$, $P=0.799)$, however, 2 -year recurrence rates between the three groups, showed statistically differences $\left(x^{2}=\right.$ 6.164, $P=0.046)$, as shown in Table 1 . Two-year recurrence rates were compared in the three groups; between the AFP-negative and AFP-low groups, and the AFP-high and AFP-low groups, the differences were not statistically significant $(P>0.05)$; between the AFPnegative and the AFP-high group the difference was statistically significant $(P<0.05)$, as shown in Table 2 . In all the 108 patients who underwent hepatectomy, 33 patients had recurrence within 2 years. Among them, six patients had a second surgical excision, seven had microwave ablation therapy, eighteen had trans-hepatic arterial chemotherapy and embolization, and two patients had no further treatment.

The Kaplan-Meier method was employed to analyze the correlation between preoperative serum AFP levels and the prognosis of HCC. The survival rates in the three groups of patients at $6,12,18$, and 24 months are shown in Table 1, and the survival curves in Figure 1. Our results show that higher preoperative AFP levels correlate with poorer prognosis. Among them, the survival rates at 18 months $\left(X^{2}=7.647, P=0.022\right)$ and 24 months
Table 1 Clinicopathologic variables in 108 patients with hepatocellular carcinoma

\begin{tabular}{|c|c|c|c|}
\hline Variable & AFP negative & AFP low & AFP high \\
\hline Age at diagnosis, years, mean $\pm \mathrm{SD}$ & $52.5 \pm 8.6$ & $52.1 \pm 7.8$ & $52.7 \pm 6.9$ \\
\hline Gender, male/female & $34 / 7$ & $20 / 8$ & $34 / 5$ \\
\hline HBsAg-positive & 37 & 27 & 38 \\
\hline Family history of liver cancer & 6 & 3 & 8 \\
\hline Family history of HBV infection & 11 & 7 & 16 \\
\hline No family history of liver disease & 24 & 18 & 15 \\
\hline Tumor number $=1$ & 35 & 21 & 28 \\
\hline Tumor number $\geq 2$ & 6 & 7 & 11 \\
\hline Tumor diameter, $\mathrm{cm}$, mean \pm SD & $5.9 \pm 6.9$ & $5.2 \pm 4.5$ & $5.0 \pm 3.9$ \\
\hline \multicolumn{4}{|l|}{ Portal vein tumor thrombus } \\
\hline No & 37 & 23 & 33 \\
\hline Yes & 4 & 5 & 6 \\
\hline \multicolumn{4}{|l|}{ Adjacent tissue invasion } \\
\hline No & 39 & 24 & 34 \\
\hline Yes & 2 & 4 & 5 \\
\hline \multicolumn{4}{|l|}{ Lymph node invasion } \\
\hline No & 39 & 24 & 37 \\
\hline Yes & 2 & 4 & 2 \\
\hline \multicolumn{4}{|l|}{ Cell differentiation ${ }^{*}$} \\
\hline Well-differentiated & 14 & 1 & 1 \\
\hline Moderate & 24 & 25 & 33 \\
\hline Poor & 3 & 2 & 5 \\
\hline \multicolumn{4}{|l|}{ Microscopic invasion $^{*}$} \\
\hline No & 25 & 7 & 8 \\
\hline Yes & 16 & 21 & 31 \\
\hline \multicolumn{4}{|l|}{ Nerve invasion } \\
\hline No & 39 & 25 & 39 \\
\hline Yes & 2 & 3 & 0 \\
\hline \multicolumn{4}{|l|}{ Lymph node metastasis } \\
\hline No & 39 & 27 & 37 \\
\hline Yes & 2 & 1 & 2 \\
\hline \multicolumn{4}{|l|}{ Fibrosis } \\
\hline 0 to 4 points & 2 & 3 & 2 \\
\hline 5 to 6 points & 39 & 25 & 37 \\
\hline \multicolumn{4}{|l|}{ Recurrence rate, n (\%) } \\
\hline 1-year & $7(17.1)$ & $6(21.4)$ & $10(25.6)$ \\
\hline 2-year ${ }^{*}$ & $8(19.5)$ & $7(25.0)$ & $18(46.2)$ \\
\hline \multicolumn{4}{|l|}{ Survival rate, n (\%) } \\
\hline 6-month & $38(92.7)$ & $25(89.3)$ & $33(84.6)$ \\
\hline 12-month & $35(85.4)$ & $24(85.7)$ & $28(71.8)$ \\
\hline 18-month ${ }^{*}$ & $35(85.4)$ & $22(78.6)$ & $23(59.0)$ \\
\hline 24-month ${ }^{*}$ & $33(80.5)$ & 20 (71.4) & $21(53.8)$ \\
\hline
\end{tabular}

Results are presented as number of patients unless stated otherwise. ${ }^{*} P<0.05$. AFP, alpha-fetoprotein. 
Table 2 Paired comparisons between three groups of patients with hepatocellular carcinoma

\begin{tabular}{lcccc}
$\begin{array}{l}\text { Comparison } \\
\text { content }\end{array}$ & $\begin{array}{c}\text { Test } \\
\text { statistic }\end{array}$ & $\begin{array}{c}\text { AFP-negative } \\
\text { versus AFP- } \\
\text { low group }\end{array}$ & $\begin{array}{c}\text { AFP-negative } \\
\text { versus AFT- } \\
\text { high group }\end{array}$ & $\begin{array}{c}\text { AFP-low } \\
\text { versus AFP- } \\
\text { high group }\end{array}$ \\
\hline Cell & $q$ & 3.95 & 5.56 & 1.47 \\
differentiation & $P$ & $<0.05$ & $<0.05$ & $>0.05$ \\
Microscopic & $q$ & 4.76 & 5.89 & 0.61 \\
invasion & $P$ & $<0.05$ & $<0.05$ & $>0.05$ \\
18-month & $q$ & 1.03 & 3.74 & 2.36 \\
survival rate & $P$ & $>0.05$ & $<0.05$ & $>0.05$ \\
2-year & $q$ & 0.92 & 3.57 & 2.31 \\
survival rate & $P$ & $>0.05$ & $<0.05$ & $>0.05$ \\
2-year & $q$ & 0.45 & 3.32 & 2.47 \\
recurrence rate & $P$ & $>0.05$ & $<0.05$ & $>0.05$ \\
\hline
\end{tabular}

AFP, alpha-fetoprotein.

$\left(X^{2}=6.725, P=0.035\right)$ were statistically different between the three groups. On paired comparisons, the differences were not statistically significant $(P>0.05)$ in the AFP-negative compared to the AFP-low group, or in the AFP-low compared to the AFP-high group, whereas the difference was statistically significant $(P<0.05)$ in the AFP-negative compared to the AFP-high group, as shown in the Table 2.

\section{Multivariate analysis}

We performed univariate analysis of risk factors for HCC postoperative recurrence and survival, including age, gender, HBsAg-positive status, family history of liver cancer, degree of fibrosis, tumor volume, tumor diameter, and AFP level. Only tumor diameter and AFP level were statistically significant $(P<0.05)$, as shown in Table 3 . Moreover, on multiple logistic regression analysis, tumor diameter and preoperative serum AFP levels were closely correlated with HCC postoperative survival rates $(P<0.05)$, as shown in Table 4.

\section{Discussion}

Primary liver cancer is a common malignant tumor. In many countries, including China, the incidence, recurrence and mortality rates of liver cancer remain high. Clinical studies have shown that there is a close relationship between the level of serum AFP and HCC incidence, recurrence and metastasis, and serum AFP level has been used as the main index of prediction for $\mathrm{HCC}$ prognosis after hepatectomy $[5,10,11]$.

From pathological studies, there is literature showing that in normal liver tissue and serum AFP-negative HCC, AFP and AFP receptors are not expressed; AFP receptors are expressed only in the AFP-positive HCC tissues [12]. Other scholars conducted a comparative study of the ultrastructural and immunohistochemical

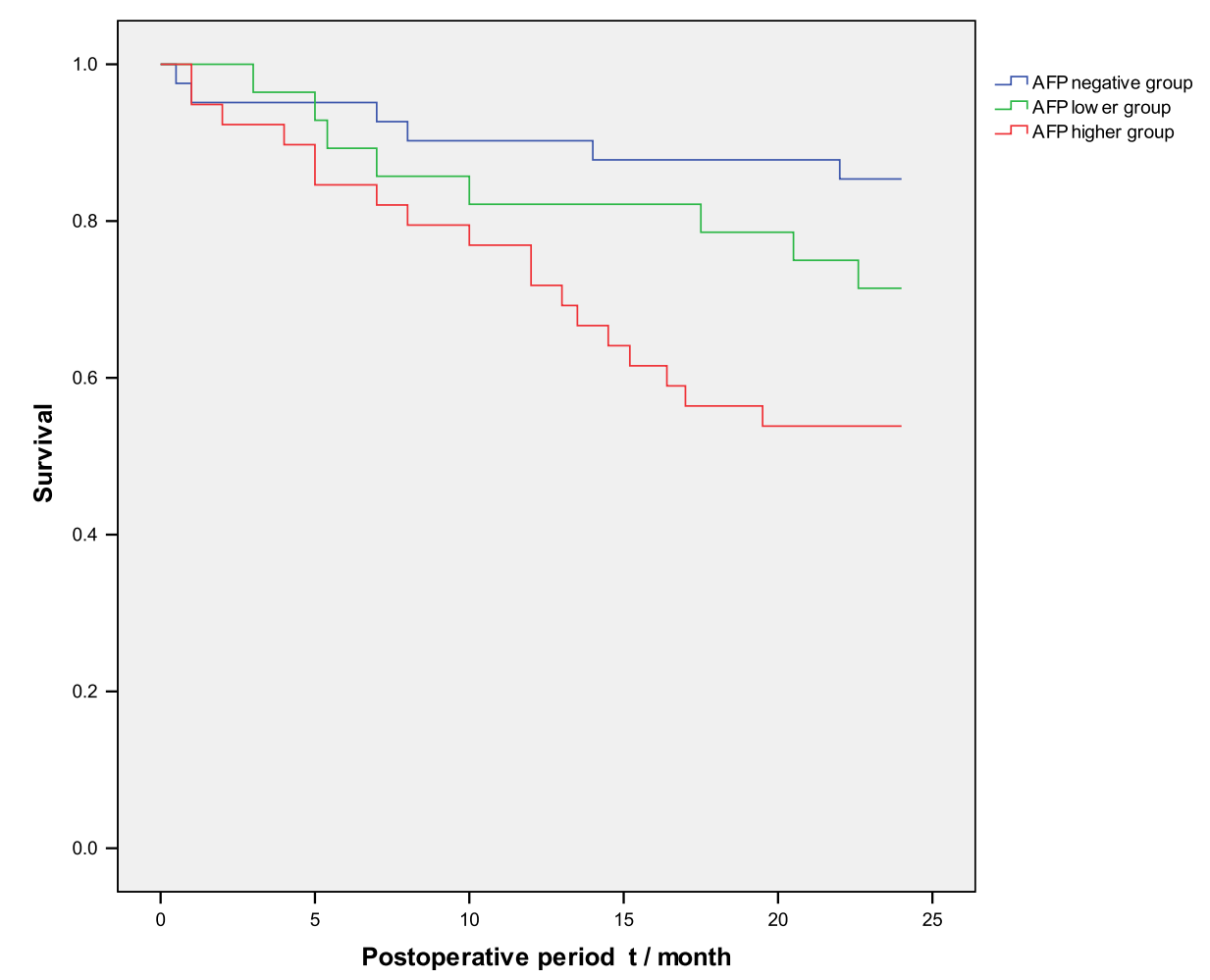

Figure 1 Postoperative survival curve for three groups of patients with hepatocellular carcinoma. AFP, alpha-fetoprotein. 
Table 3 Univariate analysis for hepatocellular carcinoma postoperative prognosis

\begin{tabular}{|c|c|c|}
\hline & Recurrence $(P)$ & Overall survival $(P)$ \\
\hline Age at diagnosis, years & 0.971 & 0.198 \\
\hline Gender, male versus female & 0.056 & 0.701 \\
\hline $\mathrm{HBsAg}$, negative versus positive & 0.088 & 0.102 \\
\hline $\begin{array}{l}\text { Family history of liver cancer, no } \\
\text { versus yes }\end{array}$ & 0.442 & 0.322 \\
\hline Tumor number, 1 versus $\geq 2$ & 0.030 & 0.150 \\
\hline $\begin{array}{l}\text { Tumor diameter, }<5 \\
\text { versus } \geq 5 \mathrm{~cm}^{*}\end{array}$ & 0.029 & 0.004 \\
\hline $\begin{array}{l}\text { Fibrosis, } 0 \text { to } 4 \text { points versus } 5 \\
\text { to } 6 \text { points }\end{array}$ & 0.717 & 0.837 \\
\hline AFP, $\leq 400$ versus $>400 \mathrm{ng} / \mathrm{mL}^{*}$ & 0.024 & 0.009 \\
\hline
\end{tabular}

AFP, alpha-fetoprotein. ${ }^{*} \mathrm{P}<0.05$.

features of the AFP-negative and -positive HCC tissues [13], and found the TN (Thomsen-Friedenreich-related antigen) protein expression level and positive rate in an AFP-negative group was significantly higher than in an AFP-positive group. The expression of AFP in the AFP-negative group was significantly lower than in the AFP-positive group. Under the electron microscope, AFPnegative HCC cells show simple organelles and rich free ribosomes; in AFP-positive ones, rich organelles, particularly the rough endoplasmic reticulum, and mitochondria and Golgi complex can be clearly observed in the cytoplasm. Whether these features are associated with AFP expression in HCC needs further study.

Through the retrospective study on the 108 patients with $\mathrm{HCC}$, we found that the degree of differentiation in the AFP-negative group was higher than that in the AFP-low and the AFP-high groups, and the vascular infiltration rate in the AFP-negative group was lower than that in the other two groups, though the differences were not statistically significant between the AFP-low group and AFP-high group. Tumor size, number of portal vein tumor thrombi, adjacent organ invasion and lymph node involvement were not significantly different among the three groups. However, the above pathological characteristics were less severe in terms of malignant features in the AFP-negative than in the AFP-positive group, which might explain its better prognosis. On follow up, there were no significant differences in recurrence or survival rates between the three groups during the first 12 months. On 24-month follow up, patients in the
AFP-negative group had a lower recurrence rate and higher survival rate when compared with the AFP-high group; however, the differences between the AFP-low and the AFP-high group were not significant. We also observed remarkable pathologically different features in the AFP-negative compared to the AFP-low group; however, the recurrence rate and survival rate were not significantly different. Our results showed that patients who had higher preoperative AFP levels were more likely to experience recurrence on short-term follow up. We need longer a follow-up period to confirm the long-term prognosis.

\section{Conclusions}

In summary, based on the results of the current study, we revealed that the extent of malignancy and long-term recurrence rate of AFP-negative HCC is lower, survival rate is higher, and prognosis is better. Therefore, preoperative serum AFP level has considerable predictive value for the malignant features and prognosis for patients with HCC. Meanwhile, multiple logistic regression analysis indicated that preoperative serum AFP level $(>400$ $\mathrm{ng} / \mathrm{mL}$ ) was an independent prognostic factor for HCC postoperative survival rates. Results from other studies also showed the AFP level was an important prediction factor for the recurrence and prognosis of HCC after resection, transarterial chemoembolization (TACE) or radiofrequency ablation (RFA) treatment [6,14-16], and it could be used to evaluate the prognosis of HCC as an independent influential factor $[17,18]$.

For years, radical hepatectomy has been considered the standard treatment for resectable primary carcinoma [19]. From the results of this study, hepatectomy was shown to be less effective in HCC patients with higher preoperative AFP levels $(>400 \mathrm{ng} / \mathrm{mL}$ ) compared to the AFP-negative patients, and similar results were reported in other studies [12]. Therefore, comprehensive therapy, needs to be considered as well as surgery, in patients with HCC and higher AFP levels (> $400 \mathrm{ng} / \mathrm{ml}$ ); a combination with postoperative TACE or portal vein chemotherapy may lead to a better prognosis [12]. On the other hand, for the HCC patients with AFP levels between 20 and $400 \mathrm{ng} / \mathrm{mL}$, the extent of malignancy is higher than that in AFP-negative patients, and long-term prognosis after resection need to be further studied; our group will continue to follow up these patients. Close follow

Table 4 Multiple regression analysis for hepatocellular carcinoma postoperative prognosis

\begin{tabular}{|c|c|c|c|c|}
\hline & \multicolumn{2}{|c|}{ Recurrence } & \multicolumn{2}{|c|}{ Overall survival } \\
\hline & $P$ & $\mathrm{HR}(95 \% \mathrm{Cl})$ & $P$ & $\mathrm{HR}(95 \% \mathrm{Cl})$ \\
\hline Tumor diameter, $<5$ versus $\geq 5 \mathrm{~cm}$ & 0.039 & $3.787(1.172 \sim 13.343)$ & 0.021 & $4.423(1.353 \sim 17.356)$ \\
\hline $\mathrm{AFP}, \leq 400$ versus $>400 \mathrm{ng} / \mathrm{mL}$ & 0.044 & 2.153(1.121 10.354) & 0.035 & $3.875(1.207 \sim 15.573)$ \\
\hline
\end{tabular}


up is needed of patients with preoperative AFP levels higher than $20 \mathrm{ng} / \mathrm{mL}$.

In addition, in this study we found the degree of differentiation of AFP-negative HCC is relatively higher, and microscopic vascular involvement is less common. In the AFP-negative HCC the rate of tumor growth would probably be expected to be relatively slow and tumor staging might be lower than in AFP-positive HCC. However, at the time of clinical diagnosis of liver cancer, the staging of AFP-negative HCC was tantamount to that in AFP-positive HCC patients, which may be related to the lack of extensive use of a highly sensitive screening index. The use of a sensitive serum biomarker to detect the early recurrence and metastasis of AFP-negative HCC is rare before signs are apparent on imaging studies. It was reported that to some extent, high-sensitivity AFP-L3, AFP-IgM complex, calcium, GP73, DCP bursin, VEGA, GPC-3, and other markers can improve the sensitivity for detection of tumor recurrence in AFP-negative HCC [20-23], and have predictive value for the HCC therapeutic effect [24]. However, they have not been applied widespread because of the limitations in the technique and the cost of detection. As a result, novel serum markers that can predict recurrence in AFP-negative HCC need further investigation.

\section{Abbreviations}

AFP: Alpha-fetoprotein; CT: Computed tomography; HCC: Hepatocellular carcinoma; RFA: Radiofrequency ablation; TACE: Transarterial chemoembolization.

\section{Competing interests}

The authors declare that they have no competing interests.

\section{Authors' contributions}

MW carried out the follow up and performed the statistical analysis. WH drafted the manuscript. TL conceived of the study, and participated in its design and coordination. All authors read and approved the final manuscript.

\section{Acknowledgements}

We thank He Kuifeng for his technical support and preparation of the material. This study was supported in part by the National Nature Science Foundation of China (grant no. 81000894).

\section{Author details}

${ }^{1}$ Cancer Center, The First Affiliated Hospital of Zhejiang University School of Medicine, Hangzhou 310003, P.R. China. ${ }^{2}$ Hangzhou Xixi Hospital, Hangzhou 310023, P.R. China.

Received: 17 February 2013 Accepted: 5 August 2013

Published: 27 August 2013

\section{References}

1. Gao JD, Shao YF, Xu Y, Ming LH, Wu ZY, Liu GT, Wang XH, Gao WH, Sun YT, Feng $X \mathrm{~L}$, Liang LM, Zhang YH, Sun ZT: Tight association of hepatocellular carcinoma with HBV infection in North China. Hepatobiliary Pancreat Dis Int 2005, 4:46-49.

2. Johnson PJ: Role of alpha-fetoprotein in the diagnosis and management of hepatocellular carcinoma. J Gastroenterol Hepatol 1999, 14:32-36.

3. Tateishi R, Yoshida H, Matsuyama Y, Mine N, Kondo Y, Omata M: Diagnostic accuracy of tumor markers for hepatocellular carcinoma: a systematic review. Hepatol Int 2008, 2:17-30
4. Snowberger N, Chinnakotla S, Lepe RM, Peattie J, Goldstein R, Klintmalm GB, Davis GL: Alpha fetoprotein, ultrasound, computerized tomography and magnetic resonance imaging for detection of hepatocellular carcinoma in patients with advanced cirrhosis. Aliment Pharmacol Ther 2007, 26:1187-1194

5. Baig JA, Alam JM, Mahmood SR, Baig M, Shaheen R, Sultana I, Waheed A Hepatocellular carcinoma (HCC) and diagnostic significance of Afetoprotein (AFP). J Ayub Med Coll Abbottabad 2009, 21:72-75.

6. Lee HY, Jung JH, Kang YS, Kim YS, Moon HS, Park KO, Lee YS, Kim SM, Seo SW, Lee SW, Kim SH, Lee BS, Kim NJ: Clinical significance of transiently elevated serum AFP level in developing hepatocellular carcinoma in $\mathrm{HBsAg}$ positive-liver cirrhosis [Article in Korean]. Korean J Gastroenterol 2004, 43:252-259.

7. Chang SK, Hlaing WW, Yu RQ, Lee TW, Ganpathi IS, Madhavan KK: Value of alpha-foetoprotein for screening of recurrence in hepatocellular carcinoma post resection. Singapore Med J 2012, 53:32-35.

8. Tangkijvanich $P$, Anukulkarnkusol N, Suwangool P, Lertmaharit $S$, Hanvivatvong $O$, Kullavanijaya $P$, Poovorawan $Y$ : Clinical characteristics and prognosis of hepatocellular carcinoma: analysis based on serum alphafetoprotein levels. J Clin Gastroenterol 2000, 31:302-308.

9. Qin LX, Tang ZY: The prognostic significance of clinical and pathological features in hepatocellular carcinoma. World J Gastroenterol 2002, 8:193-199.

10. Tong MJ, Hsien C, Song JJ, Kao JH, Sun HE, Hsu L, Han SH, Durazo FA, Saab S, Blatt LM: Factors associated with progression to hepatocellular carcinoma and to death from liver complications in patients with HBsAg-positive cirrhosis. Dig Dis Sci 2009, 54:1337-1346.

11. Chan SL, Mo FK, Johnson PJ, Hui EP, Ma BB, Ho WM, Lam KC, Chan AT, Mok TS, Yeo W: New utility of an old marker: serial alpha-fetoprotein measurement in predicting radiologic response and survival of patients with hepatocellular carcinoma undergoing systemic chemotherapy. J Clin Oncol 2009, 27:446-452.

12. Li P, Wang SS, Liu H, Li N, McNutt MA, Li G, Ding HG: Elevated serum alpha fetoprotein levels promote pathological progression of hepatocellular carcinoma. World J Gastroenterol 2011, 17:4563-4571.

13. Zheng M, Ruan Y, Yang M, Guan Y, Wu Z: The comparative study on ultrastructure and immunohistochemistry in AFP negative and positive hepatocellular carcinoma. J Huazhong Univ Sci Technolog Med Sci 2004, 24:547-559

14. Fan WZ, Yang JY, Lü MD: Transcatheter arterial chemoembolization plus percutaneous thermal ablation in large hepatocellular carcinoma: clinical observation of efficacy and predictors of prognostic factors [Article in Chinese]. Zhonghua Yi Xue Za Zhi 2011, 91:2190-2194.

15. Luo JT, Wei $X$, Zhou HY, Li Q: Influencing factors for intrahepatic distant recurrence of liver cancer after radiofrequency ablation [Article in Chinese]. Zhonghua Wai Ke Za Zhi 2009, 47:1529-1531.

16. Ikai I, Arii S, Kojiro M, Ichida T, Makuuchi M, Matsuyama Y, Nakanuma Y, Okita K, Omata M, Takayasu K, Yamaoka Y: Reevaluation of prognostic factors for survival after liver resection in patients with hepatocellular carcinoma in a Japanese nationwide survey. Cancer 2004, 15:796-802.

17. Reichman TW, Bahramipour P, Barone A, Koneru B, Fisher A, Contractor D, Wilson D, Dela Torre A, Cho KC, Samanta A, Harrison LE: Hepatitis status, child-pugh classification, and serum AFP levels predict survival in patients treated with transarterial embolization for unresectable hepatocellular carcinoma. J Gastrointest Surg 2005, 9:638-645.

18. Ha NB, Ha NB, Ahmed A, Ayoub W, Daugherty TJ, Chang ET, Lutchman GA Garcia G, Cooper AD, Keeffe EB, Nguyen MH: Risk factors for hepatocellular carcinoma in patients with chronic liver disease: a case-control study. Cancer Causes Control 2012, 23:455-462.

19. Levi DM, Tzakis AG, Martin P, Nishida S, Island E, Moon J, Selvaggi G, Tekin A, Madrazo BL, Narayanan G, Garcia MT, Feun LG, Tryphonopoulos P, Skartsis $\mathrm{N}$, Livingstone AS: Liver transplantation for hepatocellular carcinoma in the model for end-stage liver disease era. J Am Coll Surg 2010 210:727-734. 735-736

20. Kobayashi M, Hosaka T, Ikeda K, Seko Y, Kawamura Y, Sezaki H, Akuta N, Suzuki F, Suzuki Y, Saitoh S, Arase Y, Kumada H: Highly sensitive AFP-L3\% assay is useful for predicting recurrence of hepatocellular carcinoma after curative treatment pre- and postoperatively. Hepatol Res 2011 41:1036-1045

21. Jiang J, Wu C, Shen Y, Xu B, Zheng X, Li X, Xu N: Clinical application of determining serum AFP-lgM complexes for diagnosis of small hepatocellular carcinoma. Anticancer Res 2011, 31:687-691. 
22. Xu WF, Fei YM, Zhou JK, Shen HJ, Chen XF, LV QQ, Ding YY: Significance of serum golgi protein 73 (GP73), alpha-fetoprotein (AFP) and lectin-reactive alpha-fetoprotein (AFP-L3) expresssion in primary hepatic carcinoma [Article in Chinese]. Zhonghua Shi Yan He Lin Chuang Bing Du Xue Za Zhi 2011, 25:286-288.

23. Volk ML, Hernandez JC, Su GL, Lok AS, Marrero JA: Risk factors for hepatocellular carcinoma may impair the performance of biomarkers: a comparison of AFP, DCP, and AFP-L3. Cancer Biomark 2007, 3:79-87.

24. Yamamoto K, Imamura H, Matsuyama $Y$, Kume $Y$, Ikeda H, Norman GL, Shums Z, Aoki T, Hasegawa K, Beck Y, Sugawara Y, Kokudo N: AFP, AFP-L3, DCP, and GP73 as markers for monitoring treatment response and recurrence and as surrogate markers of clinicopathological variables of HCC. Gastroenterol 2010, 45:1272-1282.

doi:10.1186/1477-7819-11-212

Cite this article as: Ma et al:: Correlation analysis of preoperative serum alpha-fetoprotein (AFP) level and prognosis of hepatocellular carcinoma (HCC) after hepatectomy. World Journal of Surgical Oncology 2013 11:212.

\section{Submit your next manuscript to BioMed Central and take full advantage of:}

- Convenient online submission

- Thorough peer review

- No space constraints or color figure charges

- Immediate publication on acceptance

- Inclusion in PubMed, CAS, Scopus and Google Scholar

- Research which is freely available for redistribution 